\title{
Effects of hypertonic saline solution associated to remote ischemic perconditioning in kidney ischemia/reperfusion injury in rats ${ }^{1}$
}

Marcus Vinicius Henriques Brito', Edson Yuzur Yasojima', Sandro Percário", Rubens Fernando Gonçalves Ribeiro Júnior ${ }^{\prime \prime \prime}$, Lainy Carollyne da Costa Cavalcante ${ }^{\mathrm{IV}}$, Andrew Moraes Monteirov, Rodrigo Paracampo Couteirov, Ivone Aline da Silva Rodrigues`, Hellen Aparecida Geyer dos Santos ${ }^{v}$

'PhD, Full Professor, Department of Experimental Surgery, Universidade Estadual do Pará (UEPA), Belém-PA, Brazil. Conception, design and scientific content of the study, critical revision.

"PhD, Full Professor, Department of Biological Sciences, UFPA, Belém-PA, Brazil. Conception, design and scientific content of the study, critical revision.

I"Master, Postgraduate Program in Surgery and Experimental Research, UEPA, Belém-PA, Brazil. Statistical analysis, manuscript preparation, English language.

IVGraduate student, School of Medicine, Centro Universitário do Pará (CESUPA), Belém-PA, Brazil. Technical procedures, interpretation of data, manuscript preparation.

vGraduate student, School of Medicine, UEPA, Belém-PA, Brazil. Technical procedures, interpretation of data, manuscript preparation.

\section{Abstract}

Purpose: To evaluate the effects of hypertonic saline solution associated to remote ischemic perconditioning in renal ischemia/reperfusion injury in rats.

Methods: Twenty five male rats (Wistar) underwent right nephrectomy and were distributed into five groups: Sham group (S); Ischemia/Reperfusion group (I/R) with 30 minutes of renal ischemia; Remote ischemic perconditioning group (Per) with three cycles of 10 minutes of I/R performed during kidney ischemia; Hypertonic saline solution group (HSS) treated with hypertonic saline solution $(4 \mathrm{ml} / \mathrm{kg})$; remote ischemic perconditioning + Hypertonic saline solution group (Per+HSS) with both treatments. After reperfusion, blood samples were collected for BUN and creatinine serum levels analyzes. TBARS were evaluated in plasma and renal tissue to assess oxidative stress. Kidney histopathological examination were performed. Results: Per+HSS group showed a lower degree of renal dysfunction in relation to I/R group, whereas the technique of remote ischemic perconditioning isolated or associated with saline solution significantly reduced oxidative stress and histological damage.

Conclusion: Remote ischemic perconditioning associated or not to saline solution promoted reduction of acute renal injury induced by ischemia/reperfusion.

Key words: Ischemia. Reperfusion. Saline Solution, Hypertonic. Kidney. Rats. 


\section{- Introduction}

Ischemia/reperfusion (I/R) injury culminate in several deleterious effects for different organs. In contrast, reperfusion is the most responsible for main lesions in cells of the ischemic organ ${ }^{1}$.

Renal ischemia/reperfusion often results from shock or surgical procedures, such as renal transplantation, resection of tumors and traumas, which act as a major cause of morbidity and mortality in clinical settings ${ }^{2,3}$.

Several substances have been tested as alternatives to reduce deleterious effects of ischemia/reperfusion syndrome, such as chlorpromazine, verapamil, allopurinol, octreotide, copaiba oil, vitamins (C, D and E) and cyclosporin A. However, the effect of most them was disappointing ${ }^{1-4}$.

According to literature, crystalloid solutions, among them the hypertonic saline solution $(\mathrm{NaCl} 7.5 \%)$, showed a lower rolling of neutrophils to kidney, consequently, promoting a lower inflammatory renal injury ${ }^{5}$. However, studies to understand the current repercussions of intensity and establish the different degrees of ischemia and reperfusion are necessary.

In addition, Schmidt et al. ${ }^{6}$ reported the remote ischemic perconditioning, which consists of application of remote ischemic conditioning applied to hind limb of the swine during the time of major ischemia, which has also been shown to be effective in preventing reperfusion injury in myocardial ischemia. This protective effect was corroborated by subsequent studies involving myocardial ischemia, and the procedure was expanded to cerebral and renal ischemia ${ }^{7-9}$. Thus, the aim of this study was to evaluate the effects of hypertonic saline solution associated to remote ischemic perconditioning in renal ischemia/reperfusion injury in rats.

\section{- Methods}

All experiments were performed in accordance with Brazilian law for scientific use of animals, and this project was formally approved by the Committee of Ethics in Animal Experimentation, Universidade Estadual do Pará (Protocol 02/2014).

Twenty-five adult male Wistar rats aged 10-12 weeks (250-350g), were obtained from the Evandro Chagas Institute. The rats were maintained with free access to regular food and water, at $22 \pm 1^{\circ} \mathrm{C}$ under a 12 -h light/dark cycle.

The animals were randomly distributed into five experimental groups, each with five rats: sham group were submitted to all operative procedures, except vessels occlusion. I/R group were undergoing 30-minutes of ischemia and 72 hours of reperfusion. Remote ischemic perconditioning group (Per) were submitted to three cycles of 10-minutes of $\mathrm{I} / \mathrm{R}$ with a tourniquet on left hind limb 9 . Hypertonic saline solution (HSS) group received i.v. administration of $4 \mathrm{ml} / \mathrm{kg}^{10}$ hypertonic saline solution $7.5 \%$ after ischemic period. Remote ischemic perconditioning + HSS group (Per+HSS) received both treatments (Figure 1).

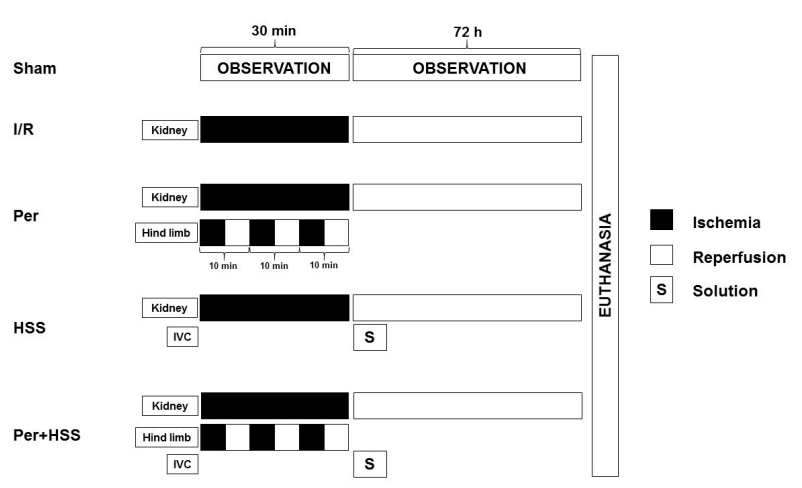

Figure 1 - Procedures between groups. IVC - inferior vena cava.

The rats were fasted overnight before the experiments, but were given free access 
to water. They were weighed and anesthetized using an intraperitoneal injection of ketamine hydrochloride $10 \%$ and xylazine hydrochloride $2 \%(70 \mathrm{mg} / \mathrm{kg}$ and $10 \mathrm{mg} / \mathrm{kg}$, respectively). During the operations, additional doses were administered if necessary.

\section{Experimental protocol}

All operations were performed under sterile conditions. An abdominal incision was made; then the left renal artery and vein were occluded with a microvascular clamp for 30-minutes; after this process, the clamp was removed and the organ was allowed to reperfusion for 72 hours. Sham operations were performed in a similar fashion, except the vessels were not clamped.

\section{Serum analysis}

After two hours of reperfusion, blood samples were collected by inferior vena cava puncture to measure blood urea nitrogen (BUN) and creatinine $(\mathrm{Cr})^{11}$ and evaluating oxidative stress by measurement of thiobarbituric acid reactive substances (TBARS) in peripheral blood and left kidney tissue fragment ${ }^{12}$.

\section{Histopathology}

The left kidney was collected $72 \mathrm{~h}$ after reperfusion. It was fixed in $10 \%$ buffered formalin, embedded in paraffin, sectioned at a thickness of $4 \mathrm{~mm}$ according to a standard procedure $^{13}$. The sections were dewaxed and gradually hydrated before being stained with hematoxylin-eosin. The presence of renal tubulointerstitial injury was defined by parameters: tubular necrosis, tubular dilation and/or atrophy, inflammatory cells infiltration and cellular edema. Kidney histopathology scores range from 0 to 4 , with the highest levels represent major damage ${ }^{14}$. The rats were euthanized by overdose of ketamine hydrochloride and xylazine hydrochloride injection (triple dose of anesthetic) at the end of the reperfusion period.

\section{Preparation of kidney tissue homogenates}

The samples were washed three times in cold normal saline solution $(0.9 \%)$. Then, the tissues were homogenized in ice-cold Tris- $\mathrm{HCl}$ buffer solution within a homogenizer for $2 \mathrm{~min}$ at $11.200 \times \mathrm{g}$. The homogenate was centrifuged at $3500 \times \mathrm{g}\left(4^{\circ} \mathrm{C}\right)$ for $60 \mathrm{~min}$, and supernatant was obtained. TBARS levels were studied in the homogenate and for a further extraction procedure, the supernatant was extracted in ethanol/chloroform mixture (5/3 v/v). After a second centrifugation at $3500 \times \mathrm{g}$ for $20 \mathrm{~min}^{15}$.

\section{Thiobarbituric acid analysis}

TBARS levels in kidney tissues and plasma were analyzed by a method based on the reaction with thiobarbituric acid at $95^{\circ} \mathrm{C}^{16}$. In the thiobarbituric acid test reaction, MDA or MDA-like substances and thiobarbituric acid react together to produce a pink pigment with an absorption maximum of $532 \mathrm{~nm}$.

\section{Statistical analysis}

BioEstat 5.4 was used and to confirm normal distribution samples by KolmogorovSmirnov test. Data are expressed as means \pm SE. ANOVA with post hoc Tukey test was applied to renal function and oxidative stress, whereas the histopathological parameters by KruskalWallis with post hoc Newman-Keuls. Values of $p<0.05$ were considered statistically significant.

\section{Results}

Compared to I/R group, all groups showed a reduction in TBARS levels, both in blood sample and renal tissue fragment. However, there was a statistically significant reduction with Per $(p=0.0320)$ and Per+HSS 
$(p=0.023)$ in accordance to $\mathrm{l} / \mathrm{R}$ group. In addition, all groups reduced BUN and creatinine levels when compared to $\mathrm{I} / \mathrm{R}$; besides, perconditioning $(p=0.027)$ and HSS $(p=0.019)$ group were statistically significant in relation to $\mathrm{I} / \mathrm{R}$ (Table 1 ).

Table 1 - Serum levels of renal function and oxidative stress (TBARS) according to groups.

\begin{tabular}{lcccc} 
& \multicolumn{2}{c}{ Renal function $(\mathrm{mg} / \mathrm{dl})$} & \multicolumn{2}{c}{ TBARS $(\mathrm{mg} / \mathrm{ml})$} \\
\cline { 2 - 5 } Groups & BUN & Creatinine & Plasma & Renal tissue \\
\hline Sham & $90.6 \pm 56.8$ & $0.89 \pm 0.37$ & $0.15 \pm 0.04$ & $0.18 \pm 0.01$ \\
I/R & $207.2 \pm 69.7^{\mathrm{a}}$ & $1.94 \pm 0.84^{\mathrm{a}}$ & $0.58 \pm 0.08^{\mathrm{a}}$ & $0.83 \pm 0.04^{\mathrm{a}}$ \\
Per & $83.3 \pm 2.8^{\mathrm{b}}$ & $0.70 \pm 0.06^{\mathrm{b}}$ & $0.07 \pm 0.20^{\mathrm{b}}$ & $0.17 \pm 0.03^{\mathrm{b}}$ \\
HSS & $59.8 \pm 1^{\mathrm{b}}$ & $0.61 \pm 0.15^{\mathrm{b}}$ & $0.12 \pm 0.03$ & $0.31 \pm 0.02$ \\
Per+HSS & $72.7 \pm 7.5$ & $0.81 \pm 0.08$ & $0.10 \pm 0.02^{\mathrm{b}}$ & $0.21 \pm 0.02^{\mathrm{b}}$ \\
\hline
\end{tabular}

Data are expressed as means \pm SD. Teste ANOVA (Tukey). ${ }^{a} p<0.05$ versus grupo Sham. ${ }^{b} p<0.05$ versus grupo I/R.

Furthermore, there was statistically significant difference between Perconditioning and Per+HSS group in all microscopic parameters: tubular necrosis (Figure 2),

\section{Tubular necrosis}

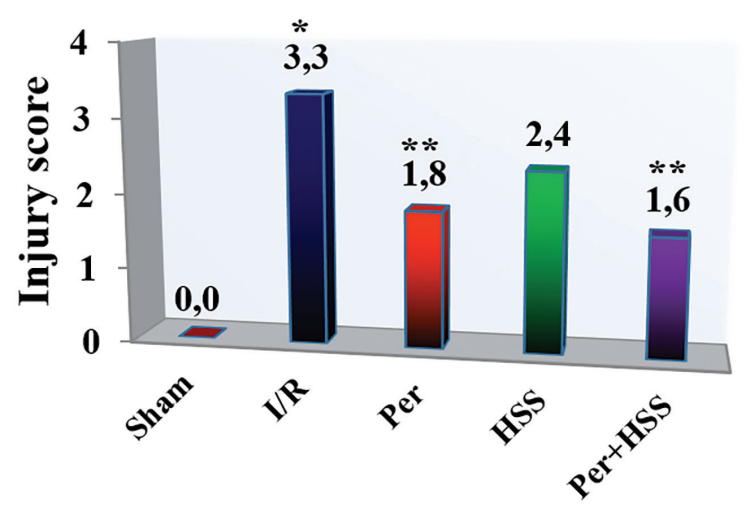

Figure 2 - Tubular necrosis between groups. ${ }^{*} p<0.05$ versus Sham group; ${ }^{* *} p<0.05$ versus I/R group. Kruskal-Wallis (Newman-Keuls) test. Source: Protocol research. tubular dilation and/or atrophy (Figure 3), inflammatory cells infiltration (Figure 4) and cellular edema (Figure 5), compared to I/R group.

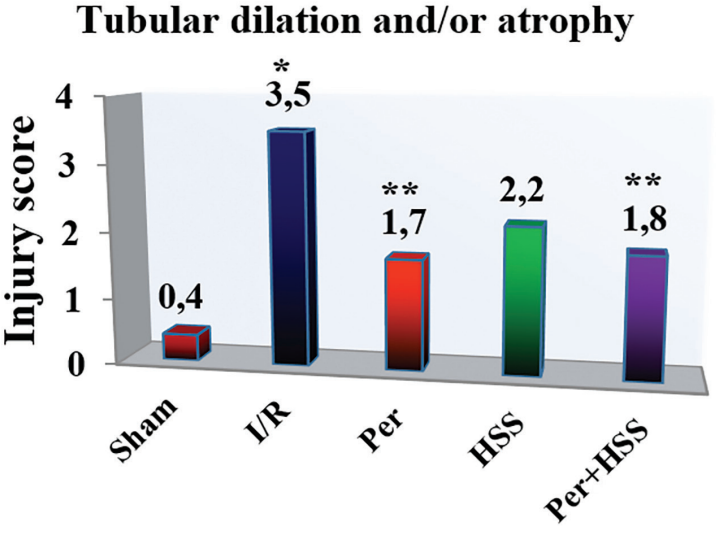

Figure 3 - Evaluation of tubular dilation and/or atrophy between groups. ${ }^{*} p<0.05$ versus Sham group; ${ }^{* *} \mathrm{p}<0.05$ versus I/R group. Kruskal-Wallis (Newman-Keuls) test. Source: Protocol research. 


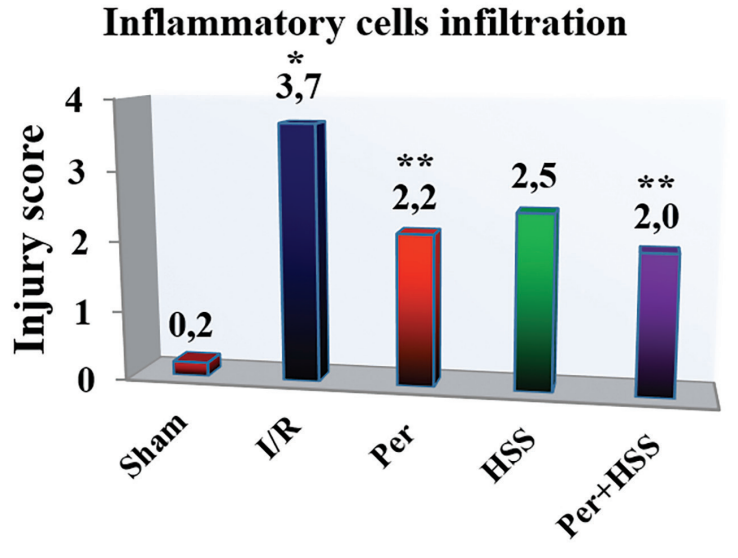

Figure 4 - Presence of inflammatory cells infiltration between groups. ${ }^{*} p<0.05$ versus Sham group; ${ }^{* *} p<0.05$ versus $\mathrm{I} / \mathrm{R}$ group. Kruskal-Wallis (Newman-Keuls) test. Source: Protocol research.

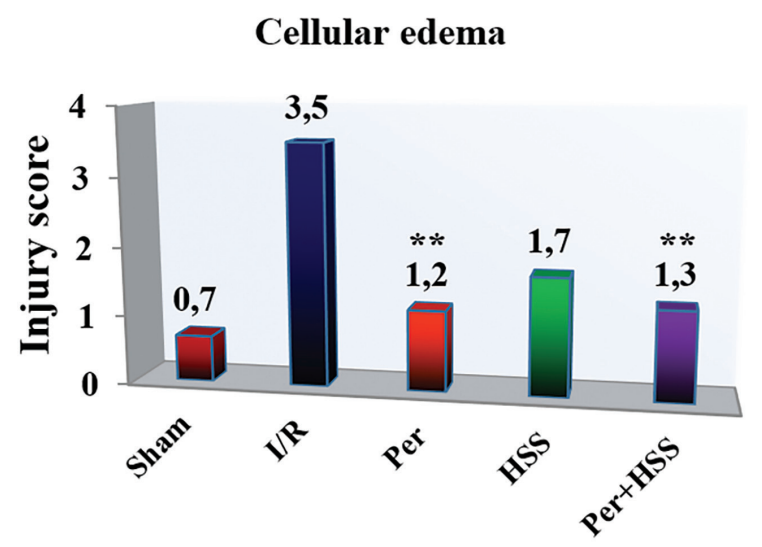

Figure 5 - Cellular edema between groups. $* p<0.05$ versus Sham group; ${ }^{* *} p<0.05$ versus I/R group. Kruskal-Wallis (Newman-Keuls) test. Source: Protocol research.

\section{- Discussion}

The present study showed that remote ischemic perconditioning isolated was as effective as Per+HSS in reducing kidney reperfusion injury in $\mathrm{I} / \mathrm{R}$ model in rats.

The protective effect of perconditioning in renal ischemia was first reported by Kadkhodaei et al. ${ }^{17}$, who promoted four cycles of $5 \mathrm{~min}$ of ischemia and $5 \mathrm{~min}$ of reperfusion, clamping left femoral artery before initiating renal reperfusion phenomenon.

Yamaki et al. ${ }^{9}$ described an alternative model of ratconditioning for renall/R performed by a tourniquet with an elastic band at the base of left hind limb. The authors performed three cycles of $5 \mathrm{~min}$ of ischemia and $5 \mathrm{~min}$ of reperfusion, which significantly reduced serum creatinine levels and histological damage.

I/R group showed significantly higher serum values and evidence of renal histological lesions than Sham, demonstrating that experimental model of ischemia was effective promoting oxidative and histological behavior as expected. In addition, $\mathrm{Cr}$ and BUN levels in Per and HSS group were significantly lower than in the $I / R$, which proves the protective effect of these treatments.

HSS group decreased parameters of renal biochemistry. Many studies have described that the use of hypertonic saline solutions promotes intravascular space expansion, which may be associated with an increase in blood volume and consequent elevation of glomerular filtration pressure, stimulating the urinary excretion of $\mathrm{Cr}$ and BUN.

A parasympathetic neural response was identified as one of the effector mechanisms of remote ischemic perconditioning, reducing nonperfusion lesion by vasospasm mechanism and contributing to the reestablishment of blood flow in microcirculation of the organ submitted to I/R injury, which may be associated with improvement of glomerular filtration capacity ${ }^{18,19}$.

In this context, application of ischemic perconditioning to a remote organ can induce the release of humoral factors - such as adenosine ${ }^{20}$, bradykinin ${ }^{21}$, and opioids ${ }^{22}$, which under local innervation, would trigger activation of neural pathways that promotes kidney protection ${ }^{19}$.

TBARS levels were significantly higher in I/R group when compared to Per and Per+HSS, 
suggesting that they were capable to maintain an antioxidant defense higher than the I/R. This maintenance of antioxidant defense, promote destruction of oxygen free radicals, reducing lipid peroxidation mediated by these reactive species originated in renal parenchyma ${ }^{23}$.

The results indicated that HSS associated or not with remote perconditioning was able to reduce intensity of renal inflammation, protecting from the injury of I/R. Hirano et al. ${ }^{24}$ showed that HSS reduced rolling of neutrophils in renal cortex. The use of this solution also showed promising results when used in mesenteric I/R models ${ }^{10,25}$.

Although the mechanisms of action of saline solutions and remote ischemic perconditioning were not fully explained, it was evidenced that in an acute ischemic injury, perconditioning isolated or associated to saline solutions obtained similar results regarding the analysed parameters, proving the effectiveness of both treatments.

\section{Conclusions}

The protective effect of remote ischemic perconditioning, when isolated or associated to hypertonic saline solution, was demonstrated in reduction of kidney ischemia/ reperfusion injury. However, there was no difference between Per and Per+HSS groups.

\section{References}

1. Brito $\mathrm{MVH}$, de Moreira RJ, Tavares ML, Carballo MC, Carneiro TX, dos Santos AA. Copaiba oil effect on urea and creatinine serum levels in rats submitted to kidney ischemia and reperfusion syndrome. Acta Cir Bras. 2005 May-Jun;20(3):243-6. doi: 10.1590/S0102-86502005000300009.

2. Mühlberger I, Perco P, Fechete R, Mayer $B$, Oberbauer R. Biomarkers in renal transplantation ischemia reperfusion injury. Transplantation. 2009 Aug 15;88(3 Suppl):S14-9. doi: 10.1097/ TP.0b013e3181af65b5.

3. Onem Y, Ipcioglu OM, Haholu A, Sen H,
Aydinoz S, Suleymanoglu S, Bilgi O, Akyol I. Posttreatment with aminoguanidine attenuates renal ischemia/reperfusion injury in rats. Ren Fail. 2009;31(1):50-3. doi: 10.1080/08860220802546313.

4. Percário S. Prevention of oxidative stress in renal ischemia-reperfusion syndrome in rats with nutritional antioxidant supplementation. Rev Nutr. 2010 Apr;23(2):259-67. doi: 10.1590/S1415-52732010000200009

5. Wade CE, Kramer GC, Grady JJ, Fabian TC, Younes RN. Efficacy of hypertonic $7.5 \%$ saline and 6\% dextran-70 in treating trauma: a meta-analysis of controlled clinical studies. Surgery. 1997 Sep;122(3):609-16. doi: 10.1016/S0039-6060(97)90135-5.

6. Schmidt MR, Smerup M, Konstantinov IE, Shimizu M, Li J, Cheung $M$, White PA, Kristiansen SB, Sorensen K, Dzavik V, Redington AN, Kharbanda RK. Intermittent peripheral tissue ischemia during coronary ischemia reduces myocardial infarction through a KATP-dependent mechanism: first demonstration of remote ischemic preconditioning. Am J Physiol Heart Circ Physiol. 2007 Apr;292(4):H1883-90. doi: 10.1152/ajpheart.00617.2006.

7. Xin P, Zhu W, Li J, Ma S, Wang L, Liu M, Li J, Wei $M$, Redington AN. Combined local ischemic postconditioning and remote preconditioning recapitulate cardioprotective effects of local ischemic preconditioning. Am J Physiol Heart Circ Physiol. 2010 Jun;298(6):H1819-31. doi: 10.1152/ajpheart.01102.2009.

8. Hahn CD, Manlhiot C, Schmidt MR, Nielsen TT, Redington AN. Remote ischemic perconditioning: a novel therapy for acute stroke?. Stroke. 2011 Oct;42(10):2960-2. doi: 10.1161/STROKEAHA.111.622340.

9. Yamaki VN, Gonçalves TB, Coelho JV, Pontes RV, Costa FL, Brito MV. Protective effect of remote ischemic per-conditioning in the ischemia and reperfusion-induce renal injury in rats. Rev Col Bras Cir. 2012 Dec;39(6):529-33. doi: 10.1590/S010069912012000600014.

10. Attuwabi B, Kozar, RA, Gates, KS, MooreOlufemi S, Sato N, Weisbrodt NW, Moore FA. Hypertonic saline prevents inflammation, injury, and impaired intestinal transit after gut ischemia/reperfusion by inducing heme oxygenase 1 enzyme. J Trauma. 2004 Apr;56(4):749-58. doi: 10.1097/01. 
TA.0000119686.33487.65.

11. Zhou JQ, Qiu T, Zhang L, Chen ZB, Wang ZS, Ma XX, Li D. Allopurinol preconditioning attenuates renal ischemia/reperfusion injury by inhibiting HMGB1 expression in a rat model. Acta Cir Bras. 2016;31(3):176-82. doi: 10.1590/S0102-865020160030000005.

12. Mahfoudh-Boussaid A, Zaouali MA, HadjAyed K, Miled AH, Saidane-Mosbahi D, Rosello-Catafau J, Ben Abdennebi H. Ischemic preconditioning reduces endoplasmic reticulum stress and upregulates hypoxia inducible factor-1-alpha in ischemic kidney: the role of nitric oxide. J Biomed Sci. 2012;19:7. doi: 10.1186/1423-0127-19-7.

13. Chen H, Xing B, Liu X, Zhan B, Zhou J, Zhu H, Chen $Z$. Similarities between ozone oxidative preconditioning andischemic preconditioning in renal ischemia/reperfusion injury. Arch Med Res. 2008;39(2):169-78. doi: 10.1016/j. arcmed.2007.09.005.

14. Liu H, Wu R, Jia RP, Zhong B, Zhu JG, Yu P, Zhao $\mathrm{Y}, \mathrm{Ge} Y Z, \mathrm{Wu} J P$. Ischemic preconditioning increases endothelial progenitor cell number to attenuate partial nephrectomy-induced ischemia/reperfusion injury. PLoS One. 2013;8(1):e55389. doi: 10.1371/journal. pone.0055389.

15. Parlaktas BS, Atilgan D, Gencten Y, Akbas A, Markoc F, Erdemir F, Ozyurt H, Uluocak N. The effects of carvedilol on ischemia-reperfusion injury in the rat testis. Int Braz J Urol. 2014 Jan-Feb;40(1):109-17. doi: 10.1590/S16775538.IBJU.2014.01.16.

16. Wasowicz W, Nève J, Peretz A. Optimized steps in fluorometric determination of thiobarbituric acid-reactive substances in serum: importance of extraction $\mathrm{pH}$ and influence of sample preservation and storage. Clin Chem. 1993 Dec;39(12):2522-6. PMID: 8252725.

17. Kadkhodaei M, Seifi B, Najafi A, Sedaghat Z. First report of the protective effects of remote per- and postconditioning on ischemia/reperfusion-induced renal injury. Transplantation. 2011 Nov 27;92(10):e55. doi: 10.1097/TP.0b013e31823411f8.

18. Donato $M$, Buchholz $B$, Rodríguez $M$,
Pérez V, Inserte J, García-Dorado D. Role of the parasympathetic nervous system in cardioprotection by remote hindlimb ischaemic preconditioning. Exp Physiol. 2013 Feb;98(2):425-34. doi: 10.1113/ expphysiol.2012.066217.

19. Lim SY, Yellon DM, Hausenloy DJ. The neural and humoral pathways in remote limb ischemic preconditioning. Basic Res Cardiol. 2010 Sep;105(5):651-5. doi: 10.1007/ s00395-010-0099-y.

20. Schulte G, Sommerschild H, Yang J, Tokuno S, Goiny M, Lövdahl C, Johansson B, Fredholm BB, Valen G. Adenosine A receptors are necessary for protection of the murine heart by remote, delayed adaptation to ischaemia. Acta Physiol Scand. 2004 Oct;182(2):133-43. doi: 10.1111/j.1365-201X.2004.01350.x.

21. Schoemaker RG, van Heijningen $C L$. Bradykinin mediates cardiac preconditioning at a distance. Am J Physiol Heart Circ Physiol. 2000 May;278(5):H1571-6. PMID: 10775135.

22. Patel HH, Moore J, Hsu AK, Gross GJ. Cardioprotection at a distance: mesenteric artery occlusion protects the myocardium via an opioid sensitive mechanism. J Mol Cell Cardiol. 2002;34:1317. doi: 10.1006/ jmcc.2002.2072.

23. Costa FLS, Teixeira RKC, Yamaki VN, Valente $A L$, Silva AMF, Brito MVH, Percário S. Remote ischemic conditioning temporarily improves antioxidant defense. J Surg Res. 2016 Jan;200(1):105-9. doi: 10.1016/j. jss.2015.07.031.

24. Hirano ES, Mantovani M, Morandin RC, Brito J, Pavani L. Total hepatic ischemia and reperfusion after state controlled hemorrhagic shock, with used of different solutions: effects of neutrophils sequestration in kidney of rats. Acta Cir Bras. 2006 Jan-Feb;21(1):31-7. doi: 10.1590/ S0102-86502006000100008

25. Jonas J, Heimann A, Strecker U, Kempski O. Hypertonic/hyperoncotic resuscitation after intestinal superior mesenteric artery occlusion: early effects on circulation and intestinal reperfusion. Shock. 2000 Jul;14(1):24-9. PMID: 10909889. 


\section{Correspondence:}

Rubens Fernando Gonçalves Ribeiro Júnior

Avenida Marquês de Herval, 1823

66087-320 Belém - PA Brasil

Tel.: (55 91)98133-7502

rubensfernandojr@gmail.com

Received: Nov 21, 2016

Review: Jan 23, 2017

Accepted: Feb 22, 2017
Conflict of interest: none

Financial source: none
${ }^{1}$ Research performed at Laboratory of Experimental Surgery (LCE), Universidade Estadual do Pará (UEPA), Belém-PA, Brazil. 